\title{
"Ah, eu acho a oralidade importantíssima!" A propósito da prática docente no ensino da oralidade
}

\author{
Débora Amorim Gomes da Costa-Maciel \\ Universidade de Pernambuco, Pernambuco-PE, Brasil. \\ deboracostamaciel@gmail.com
}

Maria Lúcia Ferreira de Figueirêdo Barbosa

Universidade Federal de Pernambuco, Pernambuco -PE, Brasil.

luciafyg@yahoo.com.br

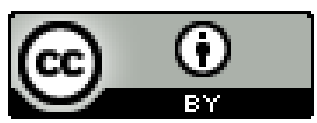

Educação: teoria e prática, Rio Claro, SP, Brasil - elSSN: 1981-8106

Está licenciada sob Licença Creative Common

\section{Resumo}

O trabalho contempla uma investigação com três professoras, do Ensino Fundamental, da Rede Pública Municipal da Região Metropolitana do Recife, com vistas à compreensão dos saberes docentes no trato com o oral, enquanto objeto didático. Foi realizada uma entrevista semiestruturada e individualizada com todos os sujeitos para sondagem de sua compreensão sobre os objetivos do ensino de língua materna, bem como para o resgate de elementos de sua prática, dentre outros aspectos investigados. Os dados foram tratados em uma perspectiva qualitativa, com o apoio da Análise de Conteúdo (BARDIN, 1997). Os resultados mostram que as docentes pesquisadas compreendem a oralidade como sendo um dos objetivos do ensino da língua portuguesa, embora suas falas demarquem com maior clareza o enfoque nos eixos de leitura, produção e análise linguística. Os resultados apontam, ainda, para uma demanda docente em relação ao que se deve ensinar nos anos de escolarização em que atuam. De modo geral, parece nem sempre haver clareza, por parte das docentes investigadas, sobre o que é o trabalho com o oral. Porém, os dados analisados vislumbram propostas didático-metodológicas que se encaminham para a exploração do eixo investigado.

Palavras-chave: Oralidade. Saberes Docentes. Ensino. 


\title{
"Ah, I think the orality is so important!" The propose of the teachers practice in orality teaching
}

\begin{abstract}
This paper is about a research with three teachers of elementary school, from municipal system of Recife's metropolitan region. We wanted to understand their knowledge about oral as a teaching object. We did a semi-structural interview and an individual one with all the subjects to explore their understanding about the objectives of teaching mother language, as well as rescue their practical elements and others. The data was treated in a qualitative view with content analysis bases in Bardin (1997). The results show us that the teachers understand the orality as one of the objectives of teaching mother language, despite their speech emphasizes reading, writing and language analysis. The results also show that there is a demand to what to teach. In general, it seems that they are not so clear about what is the working with the orality. However, the analyzed data offer methodological-teaching proposes that get fitted to explore the investigated pivot.
\end{abstract}

Keywords: Orality. Teacher knowledge. Teaching.

\section{Introdução}

O trabalho contempla uma investigação com três professoras, do 3 ao 50 anos do Ensino Fundamental, de uma escola da Rede Pública de Ensino da Região Metropolitana do Recife, com vistas à compreensão dos saberes docentes no trato com o oral, enquanto objeto didático. Foi realizada uma entrevista semiestruturada e individualizada, a partir de um agrupamento de questões com dois focos de abordagem, a saber: (1) sondar a compreensão dos sujeitos sobre os objetivos do ensino de língua materna, visto que a oralidade, enquanto eixo de ensino, também se configura como um dos objetivos do ensino de língua materna (BRASIL, 1997; MARCUSCHI, 2008; FÁVERO, 2011); (2) resgatar, através dos discursos docentes, elementos de sua prática, que dizem respeito à realização de atividades para o trato com a oralidade; as demandas de seu grupo-sala para o ensino do eixo; a compreensão de que os objetivos traçados para o ensino tenham sido alcançados; a avaliação, pelas professoras, da execução das atividades planejadas e realizadas e suas sugestões para alteração didática da proposta realizada.

Tratamos os dados qualitativamente, com base em Bardin (1997). Em virtude da necessidade de preservarmos a imagem das docentes, cada uma delas passou a ser identificada pela letra $\mathrm{P}$ (professora) e pelo ano escolar em que atuava na ocasião da pesquisa. Assim temos P3, P4 e P5 para o terceiro, o quarto e o quinto anos de escolarização, respectivamente. 
Nossos resultados apontam alguns elementos no discurso das docentes, os quais nos fazem entender que elas compreendem a oralidade como sendo um dos objetivos do ensino da Língua Portuguesa, embora não haja um explicitação clara sobre essa compreensão, uma vez que as falas analisadas demarcam o enfoque nos eixos de leitura, produção e análise linguística - apropriação da escrita alfabética. Esse dado parece revelar uma demanda docente em relação ao que ensinar nos anos de escolarização em que as professoras atuavam. No tocante a realização, demandas, objetivos e avaliação do trabalho com a oralidade nas práticas docentes, de modo geral, parece que nem sempre há clareza sobre o que é o trabalho com o oral, embora já vislumbremos propostas didáticometodológicas que se encaminham na exploração do eixo investigado.

\section{$2 \quad 0$ ensino da oralidade}

A oralidade é um tema para o qual necessitamos buscar reflexões nas esferas do saber acadêmico (CHEVELLARD, 1991) e no espaço escolar como objeto específico de conhecimento (SCHNEUWLY; DOLZ, 2004; MARCUSCHI, 2001). Essas reflexões são reforçadas pela sinalização, dos documentos oficiais, sobre a importância para o ensino desse eixo a ser ensinado no currículo de língua portuguesa (MARCUSCHI, 2001; BRASIL, 1997; FÁVERO, 2011).

Embora o ensino da oralidade seja obrigatório nas escolas brasileiras, trata-se de um eixo didático, o qual, por ser recente, no cenário dos conteúdos curriculares (BRASIL - MEC, 2010), configura-se ainda incipiente nas pesquisas e pouco presente no que diz respeito às investigações do saber docente para o seu ensino (MAGALHÃES, 2007; MARCUSCHI, 2008; MARCUSCHI; DIONIZIO, 2005; SCHNEUWLY; DOLZ, 2004).

Magalhães (2007), com base em Schneuwly e Dolz (2004), mostra que uma grande problemática na compreensão sobre o ensino do oral é o fato de a linguagem oral ser considerada, ao mesmo tempo, como prática a ser desenvolvida em produção e compreensão pelos alunos e como ferramenta das intervenções dos professores.

Segundo Magalhães (2007, p. 89), a dificuldade reside "no fato da linguagem oral ser primariamente concebida como uma ferramenta de mediação e de comunicação, fazendo com que raramente seja considerada como objeto de ensino claramente identificado". 
Mas o que é ensinar a oralidade? Para nós, é ensinar os gêneros textuais orais, o que implica observar toda a sua condição de produção e realização (CAVALCANTE; MELO 2006). Esse ensino deve ocorrer através dos gêneros textuais orais específicos (BRASIL, 1996). Os gêneros textuais, por sua concretude e historicidade, auxiliam os educadores e os educandos no processo de ensino-aprendizagem (KOCH, 2002; MARCUSCHI, 2005, 2008).

Para Schneuwly e Dolz (2004), os gêneros formais públicos devem ser ensinados, uma vez que eles constituem formas de linguagem que apresentam restrições impostas do exterior e implicam um controle mais consciente do próprio comportamento para dominálas. Mesmo sendo produzidos, em geral, de forma presencial, face a face, inscrevendo-se em uma situação de imediatismo, exigem antecipação e necessitam, portanto, de uma ação pedagógica planejada.

Ao tratar sobre o oral, Schneuwly e Dolz (2004), reforçam a necessidade de percebêlo como um eixo autônomo, mas também interdependente dos outros eixos didáticos, que, articulados, se movem para uma perspectiva de oralidade letrada. Ambos os autores reforçam a necessidade de se planejar um trabalho sistemático com o oral, de modo a favorecer no indivíduo o domínio dos jogos interativos e de estratégias de negociação em situações interlocutivas públicas.

Diante desse breve olhar teórico, nos questionamos sobre qual a compreensão do professor frente ao que lhe é proposto? De que modo ele constroi os saberes sobre o oral como objeto de ensino? Como ele analisa as suas ações frente ao que planeja para ensinar a oralidade? Algumas desses questionamentos são tomados como ponto de reflexão nesse texto, no qual pretendemos abrir caminhos para o diálogo com outras investigações.

\section{$3 \quad 0$ docente e o ensino da oralidade}

Ao introduzirmos a discussão com as docentes sobre o ensino da oralidade, buscamos entender suas percepções sobre a oralidade enquanto objeto didático, a partir da compreensão que elas tinham sobre o objetivo do ensino de língua materna para o ano de escolarização em que atuavam. Notamos que as decisões tomadas no fazer pedagógico, pelas professoras, são pautadas na escrita - leitura e produção de texto -, conforme nos mostra a afirmação de P3, a seguir: 
[...] então meu objetivo principal é esse, que eles saiam daqui lendo com compreensão e escrevendo com uma sequência lógica. Para mim esse é um dos objetivos principais, a leitura e a escrita (P3).

Dentre as preocupações enfatizadas por P3 em relação aos objetivos do ensino de língua está a formação de leitores e produtores textuais. Conforme percebemos, essa compreensão surge da necessidade de o ensino de Língua Portuguesa assumir uma perspectiva de formação para a leitura e de a escrita de textos ganhar maior destaque nas últimas três décadas (BRANDÃO; LEAL, 2005).

Em P3 vemos uma preocupação voltada para a formação de sujeitos competentes no uso da língua quando a docente expressa uma perspectiva de ensino que parece favorecer o desenvolvimento da competência textual; em particular, da capacidade de compreender e produzir variados textos (TRAVAGLIA, 1995). Esse olhar foi reiterado na continuidade de sua entrevista.

[...] Ainda essa semana eu tava mostrando a $D^{1}$ algumas produções que a gente fez. Eu trabalhei o gênero tirinha com eles, ai eles produziram um dialogo na tirinha, depois eles fizeram ao contrário, dei o diálogo e eles criaram os desenhos. Então eu tenho achado que eles estão muito melhores. Mas assim, fora essa questão de entender o que tá lendo, a questão do letramento mesmo, é isso (P3).

Notamos que, para P3, formar sujeitos leitores e produtores de texto é oportunizar experiências de letramento. Entendemos que o letramento se efetiva no desenho das propostas reais que fazem parte do cotidiano escolar do grupo-sala, despertando os educandos para a função da escrita em seu dia a dia (SOARES, 1999). Vemos que o movimento propiciado por $\mathrm{P} 3$ em relação à prática de produção de texto envolveu os alunos em uma reflexão sobre o gênero textual a tirinha. A atividade abrangeu momentos de escrita (fala dos personagens) e de produção de texto imagético, os quais, como sabemos, oportunizam uma inserção dos sujeitos na língua, fazendo-os pensar sobre o texto a ser empregado em cada situação proposta.

\footnotetext{
${ }^{1}$ Por uma questão de preservação de imagem, retiramos o nome da diretora da escola e substituímos pela letra D.
} 
No que se refere à outra docente pesquisada, P4, ao sinalizar para os objetivos do ensino da língua materna, os relacionou à preparação para a vida, de modo que a língua seja utilizada de forma competente nas esferas privada e a pública.

\begin{abstract}
Ensinar língua portuguesa na escola é ajudar o aluno se preparar para vida, pra, pra ele conviver dentro da sociedade. Porque se ele for num supermercado, ele vai ter que ler um cartaz, ele vai ter que ler uma propaganda, vai ter que ler um anúncio. Se ele for para um ponto de ônibus, ele vai que... vai ter toda uma leitura de imagem, semáforo, disso, daquilo outro [...] eles estão fazendo uma leitura. Então assim, realmente eu acho que que a língua portuguesa prepara esses meninos para conviver aí em sociedade mesmo. Conviver aí, dentro da sociedade, é é não somente do lado de fora, não somente na questão...fora de casa, da casa deles, mas também dentro de casa [...] é trabalhar sempre dando prioridade à realidade dele (P4).
\end{abstract}

Para P4, estão imbricadas, portanto, a preparação e a formação do leitor e produtor de gêneros textuais, sejam esses textos escritos ou imagéticos. Tal propósito implica o acesso à diversidade de usos da língua, em especial aos diferentes gêneros textuais, necessária ao aprendizado permanente e à inserção social (BRASIL, 1997).

Seu reconhecimento da necessidade de formar sujeitos competentes no uso da língua é coerente com uma perspectiva de ensino sistemático dos gêneros textuais públicos formais (SCHNEUWLY e DOLZ, 2004).

A visão de P4 coaduna-se com as práticas sociais de leitura e de escrita representativas do letramento social (KLEIMAN, 1996). Os eventos indiciados em seu discurso estão relacionados diretamente à necessidade de os sujeitos usarem a língua de forma adequada às diferentes linguagens que permeiam o seu meio social, bem como ao desenvolvimento da competência comunicativa (TRAVAGLIA, 1995). O movimento de P4 assume uma perspectiva de ensino que aproxima o aluno da instituição linguística, pois demonstra como a língua está constituída e como se apresenta socialmente.

Assim como P4, a docente P5 compreende os objetivos para o ensino de Língua Portuguesa como sendo relacionados à formação e ao aperfeiçoamento dos conhecimentos pelos sujeitos, bem como à sua relação direta com o uso da escrita no dia-a-dia. Vejamos um exemplo desse fato no excerto a seguir: 
[...] eu acho que a função da língua portuguesa é de aperfeiçoar os seus conhecimentos [...] então eu tenho uma preocupação muito grande, tanto é que em meu horário eu dou mais ênfase a língua portuguesa [...] não só pela leitura, mas para você compreender a visão de mundo, para você saber como agir em determinadas situações, que tem também, então você pode muito bem passar por uma rua que tem uma placa, você olhou não identificou nada e lá na frente tem um perigo. Isso também é uma leitura, só que você não esta acostumada a fazer uma interpretação, então até no seu dia você pode correr riscos se você não souber interpretar determinadas coisas. Então é por isso que eu acho que é de extrema importância (P5).

Em consonância com as demais professoras, a fala de P5 evidencia que o aperfeiçoamento do sujeito está ligado à competência leitora dos diferentes gêneros textuais que fazem parte da sua vivência. A capacidade de ler o mundo, assim como a de ler o texto, tem como princípio o desenvolvimento de competências que transcendem ao ambiente escolar de formação e visa a favorecer o uso adequado da língua nas diferentes situações da vida cotidiana.

Sob esse olhar vemos, a priori, que, em P4 e P5, o ensino de língua se desloca de uma formação que visa a formar sujeitos para agir de forma eficiente na resolução de problemas escolares, para lançá-los a desafios que transcendem os muros das escolas, habilitando-os para a vida. Em P3, parece haver uma preocupação mais voltada à resolução de tarefas escolares, ou seja, para o letramento escolar com finalidades didáticas.

Um elemento que merece ser registrado na fala das professoras é a constante menção ao uso dos gêneros textuais em suas práticas, entre estes são mencionados, por exemplo, as tiras (P3), os anúncios (P4), as placas (P5). Essa postura pode ser demarcada pela inserção desses sujeitos em um constante processo de formação continuada, promovido pela Rede em que atuam, cuja proposta pedagógica se estrutura no letramento.

No esforço de compreender como o oral se apresenta para as docentes, as questionamos sobre se havia, em sua prática, momentos reservados para o trabalho com a oralidade; quais seriam as demandas para esse eixo; se os objetivos teriam sido cumpridos; como as docentes avaliariam a execução das atividades e se fariam alguma alteração didática nos encaminhamentos planejados.

A seguir, percebemos que P3 nega, inicialmente, o investimento na oralidade: 
Não. Também só nessa área, só nessa questão da leitura, leitura individual, na leitura coletiva de um texto. Essa questão de ta conversando com eles, questionando (P3).

Conforme observamos, na fala de P3, a docente ressalta a atividade de leitura em voz alta, tanto no modo de ler coletivamente como no modo de ler individualmente, quando o aluno lê para a professora. Ambos os modos de ler são compreendidos como trabalho com a oralidade, pelo fato de a fala ter sido usada como instrumento de oralização de algo produzido na escrita.

É importante observar que as atividades que P3 afirma realizar com os alunos para tratar a oralidade são as mesmas que ela afirmou serem trazidas pelos livros didáticos. Esse cenário nos faz questionar se o LD está influenciando a compreensão de P3 sobre o que vem a ser atividade oral ou se é a compreensão da docente que se centra na percepção de atividades orais no LD, mesmo que essas atividades sejam propostas direcionadas a outros eixos como o da leitura, por exemplo.

Ao discutir a questão norteadora em tela, P4 afirma:

Então assim, toda segunda feira, eu tô trabalhando muito a questão de, a questão de de... de de, como é, hora novidade mesmo né, hora da novidade que é toda segunda que eles trazem a novidade do final de semana e a questão também de de estimular mesmo que eles falem no momento das aulas. Eu não chego com o conteúdo pronto, eu sempre estimulo para que eles falem.. Estimular e ai eu vou estimulando pra que eles falem. Então eu trabalho dessa forma a oralidade (P4).

A hora da novidade é indicada por P4 como uma das atividades realizadas por ela, com o objetivo de trabalhar a oralidade. A indicação de uso da fala, na proposta, sugere uma modalidade organizativa em atividade permanente, visto que é uma proposta constante na prática docente, em um dia específico da semana.

Como atividade, produzida e realizada oralmente, a hora da novidade coloca a fala dos alunos em evidência; oportuniza a socialização das experiências; estimula o uso da fala para um público específico - os colegas de sala; favorece o exercício do relato oral das crianças, o qual, por sua vez, oportuniza aprender a expressar-se.

Embora P3 e P4 apresentem, em suas práticas, o questionamento oral como estratégia constante, não observamos estratégias mais específicas para o trato com a argumentação nos episódios de suas falas. O que vemos são episódios de perguntas que 
parecem conduzir o aluno a se centrar no nível da opinião sobre o texto. Supomos que atividades que envolvem conversas e questionamentos entre os alunos, sem comprometimento com objetivos claros em relação ao que se deseja ensinar-aprender, tendem a cair em práticas já cristalizadas de conversação espontânea e questionamentos que não favorecem a percepção dos educandos sobre o ponto de vista do autor, sobre as reflexões acerca das estratégias argumentativas desenvolvidas por eles próprios e sobre o desenvolvimento de argumentos e contra-argumentos. (LEAL et. al, 2010)

Quanto à P5, ao ser questionada sobre a presença de atividades orais em sua prática, a docente traz para o debate a questão da variação linguística. Ela recupera uma fala apresentada, em que revela o uso, pelos alunos, de termos inapropriados para o ambiente escolar - os palavrões.

\footnotetext{
Já (trabalhei a oralidade). É pronto, foi ai que eu identifiquei as benditas palavras belas (palavrões), que eles iam para apresentação, que eu faço mais a parte de apresentação, que é bem mais fácil...Não, é tipo assim (seminários), hoje a gente trabalha determinado assunto, em grupo, então o grupo quer explicar para a turma o que foi que entendeu sobre esse assunto, ai é livre, ai aparece geralmente algum grupo que vai a frente, ela explica (P5).
}

A exposição oral aparece na fala da docente para exemplificar o seu trabalho com a oralidade. Com a atividade, os alunos são conduzidos a partilhar as suas impressões sobre assuntos trazidos por eles ou selecionados pela professora, de forma livre. Vemos que P5 enfatiza que a atividade não é um seminário, mas sim um momento em que os grupos expressam livremente suas opiniões sobre o tema em pauta.

Podemos inferir que essa negação da professora, em relação ao gênero textual seminário, pode se dever a dois elementos: o primeiro diz respeito à própria organização do gênero textual seminário, que demandaria um planejamento explícito por parte dos alunos, para efetivá-lo; o segundo diz respeito à dinâmica estabelecida pela docente para a realização de uma atividade que envolva o grupo-sala, em uma proposta menos estruturada do ponto de vista didático, o que oportuniza aos alunos ficarem livres para participar ou não do debate.

Ressaltamos a liberdade sinalizada por P5 no desenrolar da proposta, visto que elementos significativos no trato com o oral poderiam não ter envolvido a reflexão sobre o gênero, ainda que este seja oral por excelência. Sabemos que são necessárias tarefas estruturadas do ponto de vista metodológico e didático para que se possa efetivamente 
ensinar a oralidade. Não basta, portanto, se apoiar apenas em um gênero oral como veículo de uso da fala em voz alta.

O segundo foco, da abordagem das questões da entrevista, diz respeito às demandas docentes no sentido de promover as atividades orais ou atividades tomadas como sendo de oralidade. Nessa investigação vemos que duas razões desenham a prática das professoras: a primeira está relacionada à dificuldade dos alunos de se expressarem, por conta da timidez (P3 e P4); a segunda está ligada à necessidade de ensinar o uso da fala polida aos alunos (P5).

Vejamos o que afirma P3:

Tem assim, a oralidade envolve tudo, tem a questão do simples ato de falar, então tem alguns muito tímidos que são muito difíceis de se expor, quando fala é aquela coisa bem baixinho que pra fazer uma leitura, pra qualquer coisa desse tipo,ninguém escuta, até eles mesmo dizem; tia eu num to ouvindo nada, não estou ouvindo nada. Então essa questão até de perder o medo, perder a vergonha, alguns precisam ser trabalhados, que envolve a oralidade também (P3).

Observamos, nesse excerto, que P3 percebe a dificuldade de seus alunos se expressarem oralmente quando essas dificuldades estão ligadas às situações mais controladas de uso da fala. Falar diante dos colegas, em sala de aula, por exemplo, exige a mobilização de competências que necessitam ser ensinadas. Destacamos, dentre essas competências, o ato de manejar, em nível paralinguístico, o volume da voz para ajustá-lo com vistas a se fazer ouvir pela audiência (CAVALCANTE; MELO, 2006).

Ao abordar sua demanda para o ensino do oral, P4 evidencia algumas das necessidades sinalizadas por P3, vejamos:

Ah, eu acho a oralidade muito importantíssima, meu Deus! Assim, atualmente
estou sentindo uma dificuldade muito grande de trabalhar com esse eixo, né [...]
atualmente na... essa turma aqui ela tem essa, essa dificuldade, ela não oraliza, ela
conversa muito, né. Mas assim, quando é pra participar, quando é pra questionar,
quando é pra problematizar alguma coisa, ela é, muitas vezes eu tenho que
incentivar mesmo, né. Eu tenho que questionar e porque isso, e porque aquilo, ai
um ou outro vai respondendo, sabe. Já tive turmas mais participativas, sabe,
turmas boas em oralidade, e eu pude comprovar que na produção de texto eram
dez (P4).

Inicialmente, a docente enfatiza que compreende a importância da oralidade e confessa ter dificuldades de efetivar o ensino para o referido eixo, em virtude de seus alunos 
terem dificuldade de participar de atividades que exijam questionamento, problematização; enfim, atividades mais elaboradas, que demandem um nível maior de sistematização. Já nas instâncias que demandam menor monitoramento, os alunos sabem fazê-las com precisão, conforme relata a docente. Com vistas a superar essa dificuldade, P4 apresenta algumas atividades que visam a suprir as lacunas que são enfatizadas no excerto, a seguir.

[...] se eu vejo que a turma, que essa turma, como te falei, ela tem dificuldade em oralidade, eu tento trabalhar, não somente na questão da roda de conversa, na hora da novidade, mas também, até mesmo na hora da expli... quando estiver explicando algum assunto, seja de matemática, seja ciências, eu procuro não trazer a coisa pronta. Eu procuro fazer de uma forma que eles respondam, que eles falem, que eles conversem, que oralizem, porque pra mim essa é a dificuldade, essa é a dificuldade deles falarem. Realmente o que eu estou sentido muita dificuldade nessa turma é a questão da oralidade (P4).

As atividades indicadas acima são estruturadas do ponto de vista dos encaminhamentos didáticos no sentido de tratar as questões da oralidade. Há indícios de uma rotina planejada com momentos como rodas de conversa, hora da novidade, por exemplo, que favorecem o uso da fala em sala de aula. Até o momento, não se observa, na fala da docente, elementos metodológicos ligados à condução das questões que norteiam a realização das atividades supracitadas, no sentido de favorecerem competências orais, tais como aquelas ligadas à dimensão argumentativa.

Nas discussões sobre a demanda docente para o trato com o oral, P5 retoma a questão da polidez no uso da fala:

É como eles se tratam entre eles. Como eles falam de outras pessoas que, de casa. "A seu filho daquilo, daquela". Menino precisa não... "Ah, desculpa professora". Vem cá fulano [...] Ai foi quando eu parei, gente olha; se a gente fala é de um jeito, mas quando a gente vai falar com o público é de outra forma, se você no futuro for fazer uma conferencia, alguma coisa assim, um produto, eu até disse bem assim, se você trabalha numa empresa de grande porte, você tem que apresentar esse produto e vai ser assim [...] (P5).

A demanda de P5 se diferencia um pouco da realidade enfrentada pelas demais professoras. Sua fala sugere intervenção na escolha do registro comunicativo pelos educandos, no sentido de atingir a dimensão da polidez e do respeito entre si. O foco central da sua estratégia didática se relaciona a aspectos linguísticos aportando-se nos "atos de fala positivos" (CAVALCANTE; MELO, 2006, p. 93). 
Como estratégia didática para intervenção na demanda discente, P5 trata com os alunos sobre a forma como a fala poderia ser empregada para atingir determinados objetivos, bem como sobre a importância da multimodalidade discursiva nesse momento de produção (DIONÍSIO, 2005). Nesse sentido, busca ajudar o grupo-sala a visualizar possíveis situações reais de uso oral da língua a partir de uma situação hipotética de uma venda e de uma entrevista de emprego. Com esse movimento, P5 alerta o grupo para a necessidade de adequar o registro de acordo com as situações de produção da fala.

Para melhor compreendermos se as atividades propostas pelas docentes atingiriam os objetivos traçados por elas para o tratamento da oralidade, observamos o panorama, a seguir, quando, nas discussões sobre o cumprimento dos objetivos, P3 afirma que:

\footnotetext{
Pra alguns sim. Alguns que pegam com mais facilidade, alguns que tem uma compreensão mais clara, sim. Mas assim, eu tenho um planejamento diário, que muitas vezes eu consigo atingir outros não, hoje, ontem mesmo eu tive que desmontar todinha a paisagem no quadro. Muitas vezes não consegue atingir tudo que a gente tinha... Eu tenho um planejamento toda segunda eu trabalho com as disciplinas, ditado, na semana a gente tem uma série de atividades pra fazer (P3).
}

Observamos, no trecho ilustrado acima, que P3 faz uma avaliação geral de seu trabalho com o grupo sala, mas não menciona o cumprimento de objetivos relativos ao ensino da oralidade. As atividades por ela destacadas se relacionam à consolidação do sistema de escrita alfabético ou ortográfico, visto que o foco é no ditado, embora a docente tenha apontado demandas ligadas à exposição oral e à oralização da escrita. Esse cenário pode ser fruto da ausência de encaminhamentos didáticos definidos com objetivos específicos do oral, talvez pela necessidade de maior compreensão sobre o objeto de ensino, realidade que aponta no tópico a seguir - Da avaliação da prática.

Em P4, vemos que o cumprimento dos objetivos referentes à oralidade se relaciona à participação efetiva dos alunos nas atividades, à conversa entre eles e a professora sobre o assunto em pauta (P4), à postura crítica do grupo-sala frente a determinado tema abordado, bem como à coerência em suas posições.

[...] cumprir os objetivos seria eles é é, na minha opinião, seria eles participarem. Eles assim é é observarem, é é atingir aquele objetivo realmente pra... o que eu quero, o que eu quero e e, qual o objetivo que eu quero que eles alcancem com essa conversa né, para que eles pensem, para que eles sejam críticos mesmo, na hora de ser. Para que eles é é consigam ver detalhes, porque tem teve momentos 
aqui em sala de aula né, no decorrer de meu tempo aqui que assim, teve momentos que eles viam coisas que eu não via [...] (P4).

Segundo essa fala, a efetivação dos objetivos por parte da professora diz respeito à compreensão de que o trabalho com a oralidade é mais do que colocar os alunos para falarem sobre determinado conteúdo. É posicionar-se criticamente, argumentar, fazer-se compreendido e expressar-se de forma coerente. Quanto ao cumprimento dos objetivos ligados à oralidade, P5 os atrela à sua compreensão de um oral ajustado à norma ortográfica como notamos em um trecho de sua resposta:

\footnotetext{
Eu tinha o objetivo de fazer o quê? A se comunicar melhor. A falar melhor, que as palavras que eles falavam eram erradas, e eu não achava bom colocar no caderno faça com z faça com ch se você não sabia pronunciar corretamente. E utilizar elas no seu dia a dia, que isso ele não fazia, escrevia ruim e falava pior ainda, então eu imaginei que eles ficando a vontade na frente, tentando explicar, tentando convencer os colegas de determinada coisa eles iam ficar bem livres, e eu ia poder sondar realmente até que ponto chegar, e eles iam se policiar, tentando falar melhor (risos) (P5).
}

Parece haver o desconhecimento por parte de P5 de que a ortografia da língua padroniza a forma de escrever das palavras (MORAIS, 2003), embora, a pronúncia destas possa sofrer variações condicionadas por diferentes fatores, como demonstra Possenti (1997). A postura assumida por P5 pode gerar e reforçar o preconceito linguístico em relação ao uso da língua em sala de aula e fora dela, uma vez que se exige uma padronização da pronúncia das palavras ao se assumir que as variantes usadas pelo aluno eram ruins (TRAVAGLIA, 1995; BAGNO, 1998).

Para finalizar endereçamos uma questão às docentes, cujo propósito foi o de fazer com que elas avaliassem a sua prática quanto à realização das propostas ligadas ao ensino do oral. Nesse sentido, buscamos perceber se as professoras fariam alguma alteração em sua estratégia didática ao considerarem o trabalho que desenvolveram, ou não, com o seu grupo-sala.

Ao refletir sobre possíveis mudanças em sua prática, P3 não indica alterações e faz a justificativa de tal postura: 
É eu acho que eu preciso até estudar mais nessa área, você agora me despertando falando muito de oralidade, ta assim, eu tenho poucas idéias nisso. Não sei se até por conta das capacitações não terem nada nessa área específica, eu assim tenho poucas idéias de como trabalhar isso, então pode ser que tenha coisas que eu poderia puxar mais e realmente eu não tenho nem a visão disso. Nem de como problemática, nem de como necessidade de que eles tenham, realmente eu não...eu preciso estudar mais (P3).

A lacuna na formação de P3 é indicada como fator determinante para a ausência de propostas executadas pela docente com vista a tratar a oralidade. A necessidade de se apropriar de um saber curricular aparece na fala dessa professora, pondo em relevo lacunas na formação inicial e continuada, bem como nas estratégias didáticas.

Em P4, a hora da novidade é tomada como atividade que precisaria se estabelecer com maior sistematicidade em sua prática, sendo assim, passível de alteração.

\begin{abstract}
A hora da novidade, certo... Só que nessa turma eu senti muita dificuldade, porque é assim, na hora da novidade não é somente a questão da oralidade em si, mas existem as regras de quando um fala, outro tem que parar para ouvir, tem a questão de levantar a mão, o ouvir, que eles têm muita dificuldade de ouvir, né. Eles falam mais do que escutam, aí pronto (P4).
\end{abstract}

P4 justifica a necessidade de retomar a atividade a partir da identificação de problemas ligados ao comportamento de sua turma na realização da proposta. No caso específico, a dificuldade dos seus alunos de não compreenderem que para a efetivação da atividade (hora da novidade) é necessário respeitar as regras de convívio social.

No que diz respeito à avaliação da prática, a fala de P5 está atrelada a aspectos metodológicos da condução da atividade, bem como a objetivos ligados ao ajustamento da modalidade de produção da atividade.

\footnotetext{
Ah, eu melhoraria o seguinte, eu diminuiria os grupos que foram feitos em cinco, eu acho que eles melhorariam, seria bom, e colocaria assim algumas atividades que não precisassem deles escreverem, por que acho que só a linguagem, reforçar mais na linguagem deles sabe, a partir, e fazer como se fosse um, os grupos, uma competição entre eles, eu acho que seria mais interessante. Agora as atividades eu ainda estou vendo, que tipo de atividade poderia ser feita nesse sentido (P5).
} 
A modificação de ordem organizativa (GUIMARÃES; ALMEIDA; SILVA, 2012) aparece, em um primeiro momento, na fala da docente como passo de reestruturação da estratégia para o ensino do oral. Em um segundo momento, há uma indicação no foco da culminância da proposta, em que a alteração poderia ser feita a partir do estabelecimento de uma competição entre os alunos, pois os seus esforços se voltariam para desenvolver a linguagem oral e não a escrita. Se este momento representou para P5 uma organização na proposta, pode sinalizar que a atividade oral servia estruturalmente como preparação ou pretexto para a produção escrita, ainda que questões de variação de registro e de multimodalidade surgissem em meio à proposta.

\section{Considerações Finais}

$\mathrm{Na}$ configuração do cenário analisado, alguns elementos observados nos ajudam a compreender como os sujeitos concebem o oral enquanto objeto de ensino-aprendizagem. Os resultados do estudo mostraram que a maioria das professoras investigadas demonstrou preocupação com o uso da língua adequado às diferentes instâncias de produção, o que para elas significa preparar para a vida. Se considerarmos que o desenvolvimento desta competência evoca o ensino do oral, podemos inferir que a oralidade é enxergada como objeto que precisa ser ensinado-aprendido.

No tocante a realização de atividades orais na prática docente, tendo por foco as demandas, os objetivos, a avaliação da realização da proposta e as proposições para a alteração didática da atividade planejada e executada, o panorama observado se volta para as atividades de leitura em voz alta e conversa sobre determinado tema, citadas pelas docentes como tendo o propósito de ensinar o oral. São atividades de oralização o que representa um olhar sobre o modo de realização da atividade (forma oral) e não sobre o oral como objeto de ensino. Ao apontar objetivos traçados para ensinar a oralidade, observamos entre as falas sobre a superação da timidez, elementos que se voltam para o treino de técnicas de uso da fala em público (MARCUSCHI, 2005) e não necessariamente para um trabalho com a oralidade. Entre os elementos de demanda, foi citado o uso da fala polida, dimensão que explora a questão da adequação do registro comunicativo à esfera de produção/realização e se configura como uma atividade de exploração do oral. 
No que diz respeito às sugestões de alteração das atividades, pelas docentes, podemos compreender que a maior parte das propostas não tem como abordagem a ampliação e/ou aprofundamento dos conteúdos da oralidade. Realidade esta permeada por algumas variáveis, dentre elas, o desconhecimento do objeto em discussão (P3); a falta de compreensão das discentes sobre as atividades voltadas para desenvolver a oralidade (P4); o olhar ajustado prevalentemente às dimensões metodológicas (P5), o que pode representar a necessidade de conhecer melhor o objeto em questão.

Em síntese, duas dimensões podem ser percebidas a partir das falas docentes: a primeira diz respeito à compreensão de oralidade sem um objeto de ensino - o oral sem ensino; e a segunda, à uma oralidade a ser ensinada e aprendida, muito embora falte maior clareza sobre o que deve ser ensinado sobre o oral.

\section{Referências}

BAGNO, M. A língua de Eulália: novela sociolinguística. São Paulo: Editora contexto, 1998.

BARDIN, L. Análise de Conteúdos. Lisboa: Edições 70, 1997.

BRANDÃO, A.P.; LEAL, T.F. Em busca da construção de sentidos: o trabalho de leitura e produção de textos na alfabetização. Em: Leitura e produção de textos no processo de alfabetização. Belo Horizonte, Autêntica, 2005.

BRASIL. Secretaria de Ensino Fundamental. Parâmetros Curriculares Nacionais: Língua Portuguesa. Brasília, 1997.

BRASIL - MEC. Guia do Livro Didático - PNLD. Brasil, 2004.

BRASIL - MEC. Guia do Livro Didático - PNLD. Brasil, 2010.

CAVALCANTE, M. C. B.; MELO, C.T.V. de. Oralidade no ensino médio: em busca de uma prática. In: BUZEN, C.; MENDONÇA, M.(Orgs.). Português no ensino médio e a formação do professor. São Paulo: Parábola, 2006. p. 181-198 
CHEVALLARD, Y. La transposición didáctica: del saber sabio al saber enseñado. Buenos Aires: Aique, 1991.

DIONÍSIO, A. Multimodalidade discursiva na atividade oral e escrita. In: MARCUSCHI, L.; DIONISIO, A. (Orgs). Fala e Escrita. Belo Horizonte: Autêntica, 2005. p. 177-176.

FÁVERO, L.L; ANDRADE, M. L.; AQUINO, Z. A. Reflexões sobre oralidade e escrita no ensino de língua portuguesa. In: ELIAS, V.M. (Org.). Ensino de Língua Portuguesa: oralidade, escrita, leitura. São Paulo: Contexto, 2011. p. 13 a 27

GUIMARÃES, O. M. S. ; ALMEIDA, Lucinalva ; SILVA, E. O. P. . A produção de saberes dos professores na relação ensino, pesquisa e extensão no. In: Carlinda Leite; Miguel Zabalza. (Org.). Ensino Superior: Inovação e qualidade na docência. 1ed.Porto: CIIE, 2012, v. 1, p. 3233-3247.

KLEIMAN, Angela B. (Org.). Os significados do letramento: uma nova perspectiva sobre a prática social da escrita. Campinas, SP: Mercado de Letras, 1996.

KOCH, I.V. O Texto e a Construção dos Sentidos. São Paulo: Contexto, 2002.

LEAL, T. F. ; BRANDAO, A. C. P. ; CORREIA, E. F. ; GUERRA, S. E. M. S. . Entrevistando professoras: o que elas falam sobre o ensino da argumentação?. Educação Unisinos, São Leopoldo, RS, v. 14(3), p. 195-204, 2010.

MAGALHÃES, T. G. Concepção de oralidade: a teoria nos PCN e no PNLD e a prática nos livros didáticos. 2007. 211f. Tese (Doutorado em Letras) - Universidade Federal Fluminense, Rio de Janeiro, 2007.

MARCUSCHI, L.A. Produção textual, análise de gêneros e compreensão. São Paulo: Parábola, 2008.

In: MARCUSCHI, L.; DIONISIO, A. (Orgs). Fala e Escrita. Belo Horizonte: Autêntica, 2005. p. 13-30.

MARCUSCHI, L.A. Da Fala para a Escrita: atividades de retextualização. São Paulo: Cortez 2001. 
MORAIS, A. G. Ortografia: ensinar e aprender. São Paulo: Ática, 2003.

POSSENTI, S. Por que (não) ensinar gramática na escola. Campinas: ALB, Mercado de Letras, 1997.

SCHNEUWLY, B.; DOLZ, J. O oral como texto: como construir um objeto de ensino. In: . Gêneros Orais e Escritos na Escola. Campinas: Mercado de letras, 2004. p.149188.

SOARES, Magda. Letramento: um tema em três gêneros. São Paulo: Autêntica 1999.

TRAVAGLIA, L.C. Gramática e Interação: uma proposta para o ensino de gramática no 1 으 e 2은 graus. 3.ed. São Paulo: Cortez, 1995.

Enviado em Janeiro/2013

Aprovado em Novembro/2013 